\title{
Upper Airway Management in a Patient with an Asymptomatic and Undiagnosed Vallecular Cyst: A Challenging Situation
}

Mohamed Moutaoukil $^{1 *}$, Said Khalikane ${ }^{1}$, Abdelouahid Jaafaria ${ }^{1}$, Habib Bellamlih ${ }^{2}$, Mustapha Bensghir ${ }^{1}$, Hicham Balkhi $^{1}$, Abdelouahid Baite ${ }^{1}$

${ }^{1}$ Department of Anesthesiology and Intensive Care, Military Hospital Mohammed V, Faculty of Medicine and Pharmacy of Rabat, Mohammed V University, Rabat, Morocco

${ }^{2}$ Department of Radiology, Military Hospital Mohammed V, Faculty of Medicine and Pharmacy of Rabat, Mohammed V University, Rabat, Morocco

DOI: $10.36347 /$ simcr.2020.v08i12.016

| Received: 10.10.2020 | Accepted: 25.10.2020 | Published: 29.12.2020

*Corresponding author: Moutaoukil Mohamed

Abstract

Case Report

Vallecular cyst is a very rare lesion which can be potentially dangerous during anesthesia because they may completely obstruct the larynx or the anesthesiologist's view of the larynx causing difficult intubation and thus become life-threatening. This report describes airway management difficulties in a patient with an asymptomatic and undiagnosed vallecular cyst. Anaesthetic issues surrounding this pathology are discussed.

Keywords: vallecular cyst, ventilation, Paraglossal straight blade intubation.

Copyright $\left({ }^{\circ} 2020\right.$ The Author(s): This is an open-access article distributed under the terms of the Creative Commons Attribution 4.0 International License (CC BY-NC 4.0) which permits unrestricted use, distribution, and reproduction in any medium for non-commercial use provided the original author and source are credited.

\section{INTRODUCTION}

Airway problems are easiest to manage when they are anticipated. An unanticipated difficult airway during induction of anesthesia can be a vexing problem and can occur in patients with no obvious signs or symptoms suggesting airway difficulty. Different recommendations have been established and regularly updated for the management of these situations [1].

We describe a case where laryngeal inlet was obscured by a large vallecular cyst that was discovered during induction of general anesthesia, causing difficulty in tracheal intubation. A written consent for publication has been signed by the patient.

\section{Case Report}

A healthy 36 -year-old male (weight $67 \mathrm{~kg}$, size $1.74 \mathrm{~m}$ and body mass index $22 \mathrm{~kg} / \mathrm{m}^{2}$ ) was scheduled for elective flexible ureteroscopy for urinary stones under general anesthesia.

The patient underwent an uneventful spinal anesthesia five years prior for knee arthroscopy.

Preoperative examination did not reveal any findings that could predict airway difficulty, notably normal neck extension, mouth opening, and dentition, Mallampati score of II and thyromental distance superior to $6 \mathrm{~cm}$.
After a premedication by hydroxyzine $(75 \mathrm{mg}$ the day before and the morning of intervention), the patient was admitted to the operating room .The electrocardiogram, non-invasive arterial pressure, arterial hemoglobin oxygen saturation $\left(\mathrm{SpO}_{2}\right)$ and endtidal carbon dioxide $\left(\mathrm{ETCO}_{2}\right)$ were monitored.

After a 5-minute pre-oxygenation, Induction of anesthesia was achieved with the injection of fentanyl $(3 \mu \mathrm{g} / \mathrm{kg})$ and propofol $(3 \mathrm{mg} / \mathrm{kg})$. After verification of effective manually assisted mask ventilation, rocuronium $(0.6 \mathrm{mg} / \mathrm{kg})$ was administered to facilitate intubation.

One minute later, it was observed that the patient is not being ventilated with absent chest movement and exhaled carbon dioxide, despite attempts to optimize manipulations of the head and neck, use of adjuvants, 2-handed facemask application, and the assistance of a second operator. Even with the deepening of the anaesthesia with propofol $(1 \mathrm{mg} / \mathrm{kg})$, ventilation was still difficult and $\mathrm{SPO}_{2}$ was $97 \%$. Immediately, the patient was tried to be intubated. Unfortunately, two attempts at standard laryngoscopy, respectively with a Macintosh blade 3 and 4, allowed the identification of a mobile rounded structure completely masking the glottic stage. On the third attempt, a lesion depressible, pedicle and mobilizable appearance originating at the level of the false right vocal cord (Fig.1). The diagnosis of a laryngeal cyst is evoked. 
After these attempts, Saturation arterial in oxygen was dropping $\left(\mathrm{SPO}_{2}=95 \%\right)$. A request for help was then made near the anesthesia senior and Surgeons were asked to be standby for emergency tracheostomy, considering the high risk of losing the airway and nonavailability of a quick track.

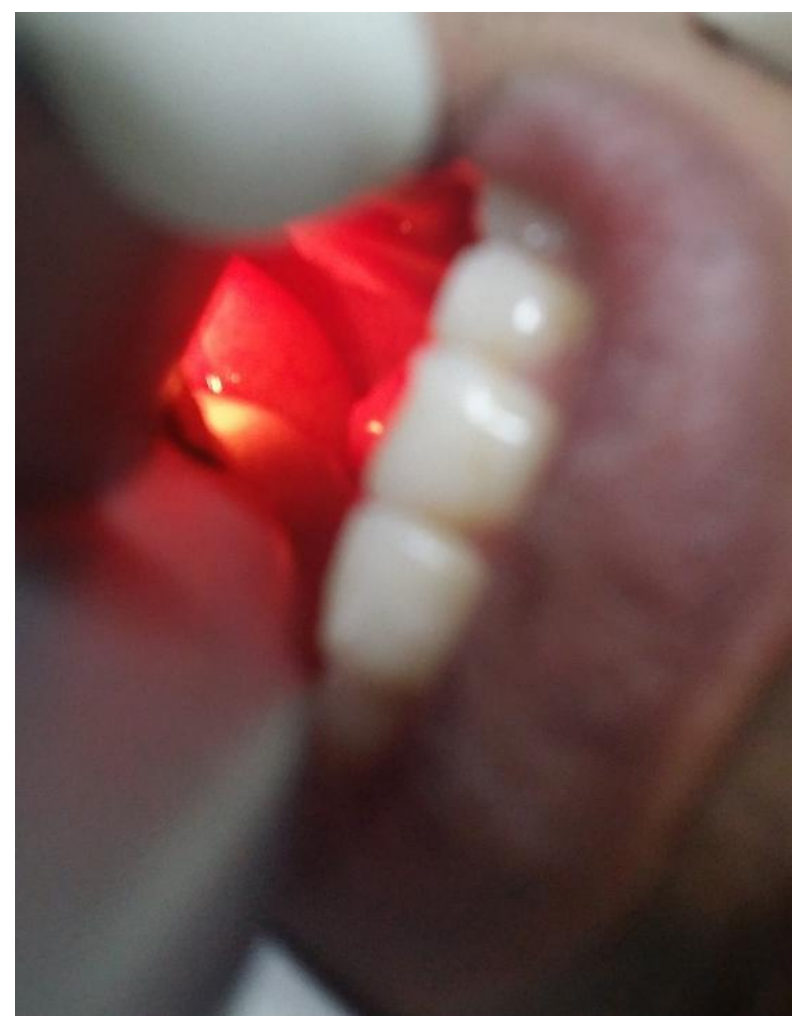

Fig-1: Vallecular cyst visualized by direct laryngoscopy

A deepening of anesthesia with a second bolus of propofol $(100 \mathrm{mg})$ and re-injection of fentanyl (50 $\mu \mathrm{g})$ and rocuronium $(20 \mathrm{mg})$ was realized.

A second attempt of ventilation with a face mask while keeping the patient's neck extended and moving the patient into the left lateral position, which allowed some ventilation with difficulty, thereby improving the saturation. (fig.2).

A repeat direct laryngoscopy again using a Miller 3 laryngoscope blade introduced by a paraglossal approach and a flexible guide (Eschmann) to push the cyst aside has enabled intubation of the trachea after a brief although limited view of the laryngeal inlet. Finally, a 7-mm ID cuffed endotracheal tube (ETT) was railroaded over the flexible guide under direct visualization with the laryngoscope. The guide was removed, and patient was ventilated with oxygenenriched air using an Ambu bag. Visible chest expansion on ventilation and bilateral breath sounds on auscultation confirmed that the endotracheal tube was correctly positioned in the trachea.

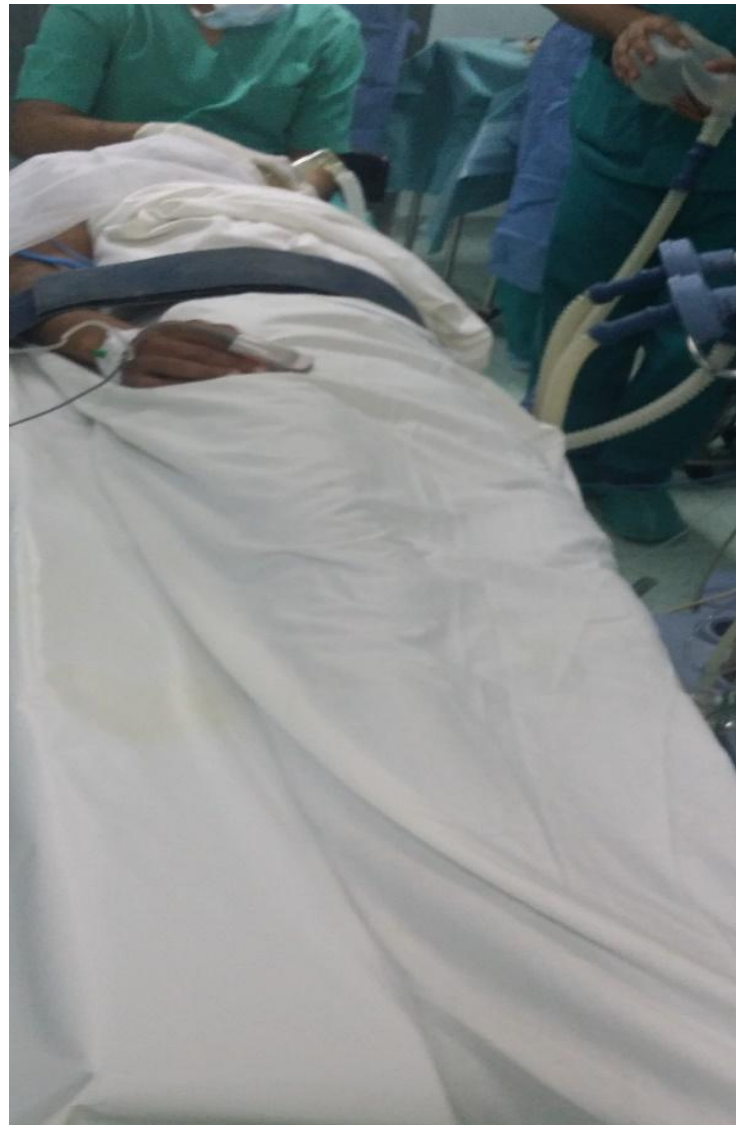

Fig-2: Patient's ventilation in left lateral position

Dexamethasone $8 \mathrm{mg}$ was administered prophylactically for potential airway edema secondary to prolonged instrumentation.

Anesthesia and the operation then proceeded uneventfully. While the patient remained anesthetized, an ear, nose, and throat surgeon (ENT) was consulted, and he decided to perform a suspension laryngoscopy that was difficult and required prolonged attempts to visualize the glottis.

In conjunction with anesthesiologist, the ENT's decision was to respect the cyst and a cross sectional imaging with CT scanning should be considered subject to the patient's airway status after awaking of anesthesia.

Anesthesia was discontinued. Neuromuscular blockade was reversed and trachea extubated, once the patient was awake and after checking for a leak around the ETT (with the patient spontaneously breathing and the cuff on the ETT deflated).

The postoperative course was uneventful, and he developed no episode of upper airway obstruction or respiratory distress. Subsequently a close Airway examination was otherwise normal except for the vallecular cyst, that was made visible during "EEEEE", phonation during tongue protrusion (fig.3). 


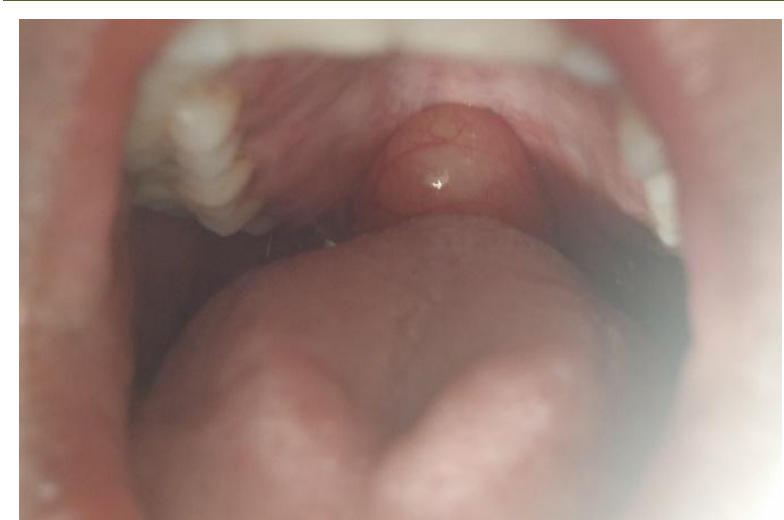

Fig-3: the vallecular cyst visible during "EEEEE" phonation and tongue protrusion

A computed tomography (CT) scan of the neck imaging was done on the same day and showed an approximately $2 * 2.5 \mathrm{~cm}$ well defined cystic lesion arising from the right vallecula, extending into the oropharynx (fig. 4).

On the 4th day of hospital admission, and under general anesthesia (airway management was easy, based on awake intubation with a nasal flexible bronchoscope), The cyst was aspirated and contained a clear, transparent fluid. Aspiration was followed by cyst excision using microlaryngeal instruments. The remaining cyst margins were then cauterized using electrocautery.

The intraoperative course was unremarkable. The cyst wall and fluid were sent for pathological examination. Culture revealed no growth. The patient was discharged on the 7th day. (fig.4 and 5)

Histopathology showed a benign cyst underneath the stratified squamous epithelium and underlying edematous stroma. The cyst is lined by flattened squamous epithelium, devoid of contents. There was no inflammation or malignancy and a final diagnosis of vallecular cyst was given.

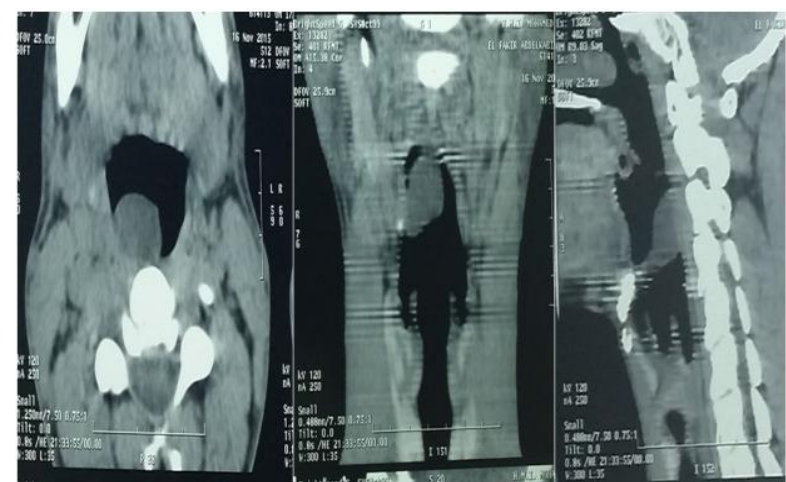

Fig-4: Computed tomographic image shows the cyst arising from the right vallecula, extending into the oropharynx

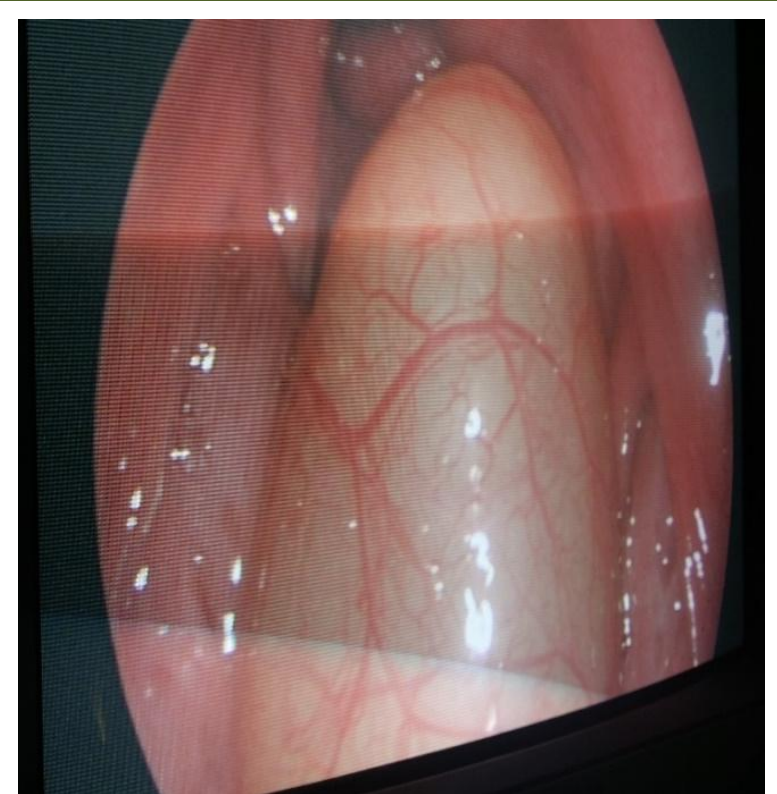

Fig-5: Examination of the intubated airway with a fiberoptic bronchoscope, demonstrating obstruction of the laryngeal inlet by the vallecular cyst. The photo was taken at the beginning of the operation with an endoscope type Olympus Evis Lucera CV-260 (Olympus Key Med UK)

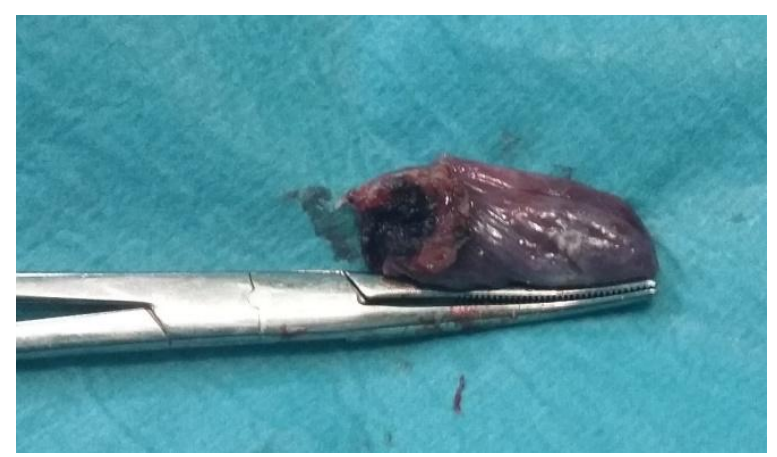

Fig-6: Image of the cyst after excision

\section{DiSCUSSION}

A vallecular cyst is a rare non-malignant mass contributing only about $5 \%$ of all benign laryngeal lesions. It may cause dysphagia or voice change but May, as in this case, be completely asymptomatic [2-4].

Vallecular cyst is a rare cause of difficult mask ventilation and intubation. The difficulty of managing the upper airways arises especially with asymptomatic cysts. Various cases of vallecular cyst discovered during intubation have been reported [4-19]. After they have been reviewed, it was observed that no specific technique has been clearly outlined for such a tricky situation .The clinical features and management of these cases are outlined in table 1 .

When an asymptomatic vallecular cyst became apparent during induction of general anesthesia and causing diffuculty intubation, the patient's oxygenation and ventilation must be ensured. In our patient and after the curarization, ventilation with the facial mask, which was easy, became impossible. This was probably due to 
loss of pharyngeal tone allowing the cyst to fall back and occlude the glottic inlet $[4,12]$. Moving the patient into the lateral position had relieved the airway obstruction and improved ventilation, but this would have put the patient in an unsuitable position for tracheostomy [4].

In the case of difficult intubation, it should be remembered that one must limit repeated attempts at laryngoscopy to avoid hemorrhage and edema $[19,20]$.

If the patient cannot be intubated or ventilated by mask, then a "cannot ventilate, cannot intubate" (CVCI) situation exists and immediate life-saving rescue maneuvers must be instituted.

Difficult airway guidelines such as those of the French Society of Anesthesia and Resuscitation (SFAR) recommend insertion of a supraglottic airway device (Laryngeal Mask Airway, esophageal-tracheal Combitube, and transtracheal jet ventilation (TTJV)) as appropriate nonsurgical solutions for a CVCI situation for persistent difficult or impossible mask ventilation not amenable to optimization maneuvers[20].

However, the first two options may fail to solve the problem, since both provide supraglottic ventilatory mechanisms. Moreover, as these devices are inserted blindly into the airway, they might traumatize the cyst, causing rupture of the cyst or its blood vessels, with resultant bleeding and aspiration [4, 12]. For this reasons, passage of a laryngeal mask was considered and rejected in our patient, with the additional concern of further posterior displacement and fixation of the mass leading to complete airway occlusion.

The literature on the use of laryngeal mask airways (LMAs) with asymptomatic vallecular cysts is limited to 2 reports, and in both cases, this device did not ensure the ventilation of the patients [5, 7]. However, Kihara reported the successful use of the LMA ( Intubating LMA) in a patient with a symptomatic vallecular cyst while explaining LMA insertion initially can failed to provide a clear airway, but withdrawal and reinsertion ("up-down" maneuver) can corrected this[21]. He postulates that the cyst was downfolded into the LMA bowl following initial placement and that withdrawal returned it to the correct position.

Therefore, an incidental vallecular cyst may be a limitation in the applicability of difficult airway algorithms in events of difficult ventilation, necessitating a lower threshold for emergent invasive airway access such as TTJV or surgical airway. Although emergency tracheostomy was previously described in the management of an asymptomatic epiglottic cyst [8].
In many previous case reports and in our patient, intubation was performed by paraglossal laryngoscopy with Miller blade and the aid of a gum elastic bougie to displace the pedunculated cyst, facilitated exposure of the laryngeal inlet [6]. The cause of improved view by paraglossal straight blade technique is due to contribution from both the paraglossal approach and the straight blade laryngoscope. The mechanism for improved visualization is due to reduction of soft tissue compression (central component of line of sight) and lowering of proximal end of line of sight $[6,12]$.

The use of alternatives methods and different devices, alone or in combination, have been reported (table 1): Aspiration of the cyst via a needle and syringe [2, 19], retrograde tracheal intubation [14], video laryngoscope $[18,19]$ and flexible fiberoptic laryngoscope [9]. This latter device should be used as a first option when a laryngeal cyst that obstructs the view of the laryngeal inlet is encountered. The main attribute of the flexible fiberoptic laryngoscope is its ability to be easily molded to the patient's airway anatomy, as opposed to rigid instruments that force the patient's airway anatomy to conform to the instrument. The patient should be allowed to wake up, since a return to spontaneous ventilation facilitates fiberoptic exposure of the larynx. Whenever the base of the cyst is pedunculated (as in the present case), the natural act of breathing or swallowing may cause changes in its position allowing a brief visualization of the laryngeal inlet and advancement of the tube without traumatizing the cyst [12].

Emergent ENT consultation may be sought for airway management assistance on vallecular cyst discovery where appropriate such as highly obstructive cysts, difficult ventilation, and multiple failed attempts at laryngoscopy or intubation [4]. Such a consultation is currently not described in current difficult airway guidelines, which do not account for potential airway management interventions specific to vallecular cysts, namely emergent cyst aspiration and suspension laryngoscopy. Depending on ventilation status, controlled decompression using a needle aspiration technique to improve laryngoscopy may be possible; however, once the airway is secured the immediate or remote surgical management of a laryngeal cyst discovered during intubation is unclear. The attitude varies according to the cases reported (table 2). Airway obstruction remains the main risk after extubating [19].

Various surgical techniques have been described for the management of vallecular cysts; these include aspiration, marsupialization, and excision [22, 23]. Marsupialization of the cyst is the preferred treatment. Different modalities have been used for this purpose; these include electro cautery, $\mathrm{CO} 2$ laser, coblation, tonsillar snare, microdebrider, or microlaryngoscopic instruments. Compared to complete 
excision, the recurrence rate after marsupialization has been reported as negligible [4, 9].

\section{CONCLUSiON}

Airway problems are easiest to manage when they are anticipated. An asymptomatic vallecular cyst is a rare cause of difficulty upper airway management.
Intubation may require a combination of devices. Paraglossal straight blade technique for intubation can thus be an alternative in cases where airway pathology precludes use of traditional intubation techniques and must be taught and learned. Preparedness for tracheostomy should always be present, especially in the case of "can't ventilate- can't intubate".

Table-1: Asymptomatic vallecular cyst discovered during general anesthesia. Previous case summaries

\begin{tabular}{|c|c|c|c|c|}
\hline Author & Cyst size & BMV & Management of case & Complications \\
\hline Evans $^{5}$ & $?$ & Easy & $\begin{array}{l}\text { Withdraw after cyst discovery: } \\
\text { intubation not attempted (BMV } \\
\text { throughout case) }\end{array}$ & No \\
\hline Kamble[6] & $2 \mathrm{~cm}$ & Difficult & DL: Miller 2, stylet & No \\
\hline Kariya[7] & $?$ & Easy & $\begin{array}{l}\text { FOB assisted by the use of a direct } \\
\text { laryngoscope }\end{array}$ & No \\
\hline Kyle[8] & $5 \mathrm{~cm}$ & Impossible & Tracheostomy & No \\
\hline $\operatorname{Lam}[9]$ & $3 \mathrm{~cm}$ & $?$ & FOB & Profound bleeding \\
\hline Mason[2] & $4-5 \mathrm{~cm}$ & Difficult & $\begin{array}{l}\text { DL, cyst aspiration } \\
\text { Procedure was abandoned }\end{array}$ & No \\
\hline Mason[2] & $3-4 \mathrm{~cm}$ & Difficult & $\begin{array}{l}\text { Procedure was abandoned } \\
\text { DL, blade unspecified with bougie }\end{array}$ & No \\
\hline McHugh[10] & $?$ & Easy & DL, blade unspecified with bougie & No \\
\hline Millard[11] & $?$ & Easy & FOB, nasal awake & No \\
\hline Rivo[12] & $4,5 \mathrm{~cm}$ & Easy & DL: Mac 4 & No \\
\hline Sonny[13] & $3 \mathrm{~cm}$ & Easy & DL: Mac3 & No \\
\hline Vorobeichik[4] & $2 \mathrm{~cm}$ & Difficult & Retrograde intubation & No \\
\hline Yoshiyama[14] & $3 \mathrm{~cm}$ & Easy & DL: blade unspecified & No \\
\hline Yoshiyama[14] & $4 \mathrm{~cm}$ & Easy & DL: cyst aspiration & No \\
\hline Yuce[15] & $2 \mathrm{~cm}$ & Easy & DL: Magill laryngoscope blade & No \\
\hline Padfield[16] & $?$ & Crush induction & DL: blind intubation using a tube one & No \\
\hline McKiernam[17] & $3-4 \mathrm{~cm}$ & Easy & $\begin{array}{l}\text { size smaller than usual, bent into a } \\
\text { double curve on a malleable } \\
\text { introducer }\end{array}$ & No \\
\hline Bensghir[19] & $2-3 \mathrm{~cm}$ & Easy & video laryngoscopy, with bougie & No \\
\hline $\operatorname{Kim}[18]$ & $2-2.5 \mathrm{~cm}$ & difficult & Videolaryngoscopy & No \\
\hline
\end{tabular}

$\mathrm{BMV}=$ bag-mask ventilation; $\mathrm{DL}=$ direct laryngoscopy; $\mathrm{Mac}=$ Macintosh blade; $\mathrm{FOB}=$ fiberoptic bronchoscope.

Table-2: Otolaryngology (ENT) consultations and interventions for incidental vallecular cysts with extubation outcomes

\begin{tabular}{|c|c|c|c|}
\hline Author & $\begin{array}{l}\text { ENT } \\
\text { consultation }\end{array}$ & ENT intervention & Extubation \\
\hline Evans $^{5}$ & Postoperative & NA & NA (no intubation) \\
\hline Kamble $^{6}$ & Intraoperative & Excision & Uneventful in OR \\
\hline Kariya $^{7}$ & $\begin{array}{l}\text { No }\left(30^{\text {th }} \text { day }\right. \\
\text { postoperative })\end{array}$ & $\begin{array}{l}\text { Puncture of the cyst }\left(30^{\text {th }} \text { day }\right. \\
\text { postoperative })\end{array}$ & Uneventful in OR after leak test \\
\hline $\mathrm{Kyle}^{8}$ & Intraoperative & Aspiration and deroofing & ICU decannulation same day, uneventful \\
\hline $\mathrm{Lam}^{9}$ & Intraoperative & Excision & NA (no mention) \\
\hline Masson $^{2}$ & Intraoperative & Aspiration before intubation & Uneventful in OR \\
\hline Masson $^{2}$ & Postoperative & Excision & Uneventful in OR \\
\hline $\mathrm{McHugh}^{10}$ & No & NA & Uneventful in OR \\
\hline Millar ${ }^{11}$ & No & NA & Uneventful in OR \\
\hline Rivo $^{12}$ & Intraoperative & Excision & $\begin{array}{l}\text { Uneventful in OR after leak test, } \\
\text { Stridor postoperatively; resolved with dexamethasone } \\
\text { and nebulized adrenaline }\end{array}$ \\
\hline Sonny ${ }^{13}$ & Postoperative & NA & Uneventful in OR \\
\hline Vorobeichikh $^{4}$ & Intraoperative & $\begin{array}{l}\text { Biopsy, aspiration } \\
\text { Complication; rupture, airway } \\
\text { edema }\end{array}$ & Uneventful in ICU postoperative day 2 \\
\hline Yoshiyama $^{14}$ & Intraoperative & Excision & Uneventful in OR \\
\hline Yoshiyama $^{14}$ & Postoperative & NA & Uneventful in OR \\
\hline Yuce $^{15}$ & Intraoperative & Aspiration & NA (no mention) \\
\hline Padfield $^{16}$ & Postoperative & Excision & Uneventful in OR \\
\hline McKiernam $^{17}$ & NO & NA & Uneventful in OR \\
\hline Bensghir $^{19}$ & NO & NA & airway obstruction by cyst, Aspiration \\
\hline $\mathrm{Kim}^{18}$ & Intraoperative & Excision & Uneventful in OR \\
\hline
\end{tabular}

$\mathrm{NA}=$ not applicable; $\mathrm{OR}=$ operating room; ICU = intensive care unit. 


\section{REFERENCES}

1. Zeping $\mathrm{Xu}$, Wuhua Ma, Douglas L Hester, Yandong Jiang. Anticipated and unanticipated difficult airway management. Curr Opin Anaesthesiol. 2018 Feb;31(1):96-103.

2. Mason DG, Wark KJ. Unexpected difficult intubation. Asymptomatic epiglottic cysts as a cause of upper airway obstruction during anaesthesia. Anaesthesia. 1987;42:407-10

3. Arens C, Glanz H, Kleinsasser O. Clinical and morphological aspects of laryngeal cysts. Eur Arch Otorhinolaryngol. 1997;254:430-6

4. Leon Vorobeichik, Gregory M T Hare, Molly Zirkle, Marco M Garavaglia. Airway Management of Incidental Vallecular Cysts in Adults. A Case Rep. 2015 Dec 15;5(12):223-7.

5. Evans A. Difficulty in inserting a laryngeal mask airway. Anaesthesia. 1995;50:468-9

6. Kamble VA, Lilly RB, Gross JB. Unanticipated difficult intubation as a result of an asymptomatic vallecular cyst. Anesthesiology. 1999;91:872-3

7. Kariya N, Nishi S, Minami W, Funao T, Mori M, Nishikawa K, Asada A. Airway problems related to laryngeal mask airway use associated with an undiagnosed epiglottic cyst. Anaesth Intensive Care. 2004;32:268-70

8. Kyle BC, Gaylard D, Riley RH. A persistent 'can't intubate, can't oxygenate' crisis despite rocuronium reversal with sugammadex. Anaesth Intensive Care. 2012;40:344-6

9. Lam HC, Abdullah VJ, Soo G. Epiglottic cyst. Otolaryngol Head Neck Surg. 2000;122:311

10. McHugh P. Cyst of epiglottis. Anaesthesia. 1989;44:522

11. Millar SW. Unexpected difficult intubation. Anaesthesia. 1987;42:1021-2

12. Rivo J, Matot I. Asymptomatic vallecular cyst: airway management considerations. J Clin Anesth. 2001; $13: 383-6$

13. Sonny A, Nagaraj G, Ramachandran R. Asymptomatic epiglottic cyst: a rare cause of unanticipated difficult intubation. Middle East J Anaesthesiol. 2011;21:119-20

14. Yoshiyama T, Mikawa K, Maekawa N, Tanaka O, Goto R, Yaku H, Obara H. Two cases of asymptomatic epiglottic cyst confirmed by lateral cervical roentgenogram. J Anesth 1991;5:313-6

15. Yuce Y, Uzun S, Aypar U. Asymptomatic vallecular cyst: case report. Braz J Anesthesiol 2013;63:419-21

16. Padfield A. Epiglottic cysts. A case report and review. Anaesthesia. 1972; 27:84-8.

17. McKiernan EP, Meakin G: Vallecular cysts [Letter]. Anaesthesia. 1988; 43:808 -9.

18. Soo H Kim, Jason C Vitek, Minerva $P$ Kryniak, Paul S Pagel: An Unanticipated Airway Problem in a Man Undergoing Femoral-Popliteal Bypass. J Cardiothorac Vasc Anesth ,2017 Dec;31(6):2312-2314.

19. Mustapha Bensghir, Jaafar Salim Alaoui, Nouredine Drissi Kamili: Upper airway management in a patient with an asymptomatic laryngeal cyst. Can J Anaesth. 2011 Jan;58(1):1201.

20. Olivier Langeron, Jean-Louis Bourgain, Daniel Francon, Julien Amour, Christophe Baillard, Gaëlle Bouroche, Madeleine Chollet-Rivier, François Lenfant, Benoît Plaud, Patrick Schoettker, Dominique Fletcher, Lionel Velly, Karine NouetteGaulain; Difficult intubation and extubation in anaesthesia in the adult patient. Anesth Reanim. 2017; 3: 552-571

21. Kihara S, Watanabe S, Taguchi N, Brimacombe J. Airway rescue with the intubating laryngeal mask in a patient with an unexpectedly large epiglottic cyst. Anasthesiol Intensivmed Notfallmed Schmerzther. 2000;35:774-5

22. Berger G, Averbuch E, Zilka K, Berger R, Ophir D. Adult vallecular cyst: thirteen-year experience. Otolaryngol Head Neck Surg. 2008;138:321-7

23. Pagella F, Pusateri A, Matti E, Tinelli G, Benazzo M. Transoral power-assisted marsupialization of vallecular cysts under local anesthesia. Laryngoscope. 2013;123:699-701. 